Article

\title{
Evaluation of Combat Helmet Behavior under Blunt Impact
}

\author{
Carlos Moure-Guardiola ${ }^{1}$, Ignacio Rubio ${ }^{1}$, Jacobo Antona-Makoshi ${ }^{2}$, Álvaro Olmedo ${ }^{3}$, \\ José Antonio Loya ${ }^{4}$ (D) and Marcos Rodríguez Millán ${ }^{1, *(\mathbb{D})}$ \\ 1 Department of Mechanical Engineering, University Carlos III of Madrid, Avda. de la Universidad 30, \\ Leganés, 28911 Madrid, Spain; 100346468@alumnos.uc3m.es (C.M.-G.); igrubiod@pa.uc3m.es (I.R.) \\ 2 Japan Automobile Research Institute, 2530 Karima, Tsukuba, Ibaraki 305-0822, Japan; ajacobo@jari.or.jp \\ 3 FECSA Company, Calle de Acacias 3, San Sebastián de los Reyes, 28703 Madrid, Spain; aolmedo@fecsa.net \\ 4 Department of Continuum Mechanics and Structural Analysis, University Carlos III of Madrid, Avda. \\ de la Universidad 30, Leganés, 28911 Madrid, Spain; jloya@ing.uc3m.es \\ * Correspondence: mrmillan@ing.uc3m.es
}

Received: 30 October 2020; Accepted: 25 November 2020; Published: 27 November 2020

check for updates

\begin{abstract}
New threats are a challenge for the design and manufacture of modern combat helmets. These helmets must satisfy a wide range of impact velocities from ballistic impacts to blunt impacts. In this paper, we analyze European Regulation ECE R22.05 using a standard surrogate head and a human head model to evaluate combat helmet performance. Two critical parameters on traumatic brain analysis are studied for different impact locations, i.e., peak linear acceleration value and head injury criterion (HIC). The results obtained are compared with different injury criteria to determine the severity level of damage induced. Furthermore, based on different impact scenarios, analyses of the influence of impact velocity and the geometry impact surface are performed. The results show that the risks associated with a blunt impact can lead to a mild traumatic brain injury at high impact velocities and some impact locations, despite satisfying the different criteria established by the ECE R22.05 standard. The results reveal that the use of a human head for the estimation of brain injuries differs slightly from the results obtained using a surrogate head. Therefore, the current combat helmet configuration must be improved for blunt impacts. Further standards should take this into account and, consequently, combat helmet manufacturers on their design process.
\end{abstract}

Keywords: combat helmet; TBI; HIC; peak linear acceleration; blunt impact; human head; LS-Dyna

\section{Introduction}

One of the most significant challenges of the defense industry for improving the protective capacity against different load states is focused on the combat helmet. During the different conflicts in which the U.S. Army has participated since 2000, a large number of traumatic brain injuries (TBIs) have been observed as a result of more than 360,000 injuries, where $82 \%$ were classified as minor (mTBIs) [1,2].

Soldier activity in combat scenarios supposes a high exposure of the head, where it is easy to suffer falls, collisions, or even traffic accidents or failed parachute jumps, and in all cases, the most typical type of injuries are mTBIs, in which brain diffuse injuries, concussions, and contusions are the most common consequences [3,4].

However, it is not a trivial task to improve the protective performance of a combat helmet without losing the real purpose of using composite materials, which is a decrease in weight. Traditionally, combat helmets have to be subjected to ballistic standards such as STANAG 2920 [5] or NIJ 0106.01 [6] and, consequently, they are analyzed at high impact velocities for the different ammunition [7-12], also under blast loadings [13-18]. However, the military industry has not focused on analyzing the 
behavior of the combat helmet under low-velocity impact. This type of analysis is more common in the motorbike or bicycle industry because helmets must satisfy the requirements established by the ECE R22.05 [19] or EN 1078 [20] standards, respectively. Few studies have analyzed the performance of the combat helmet under low velocity impacts and its response over the user. Thus, our study is focused on verifying the performance of a current combat helmet configuration and improving the knowledge of combat helmet response under blunt impacts

Begonia et al. [21] carried out experimental low velocity impact tests of a combat helmet mounted on a combined NOCSAE head model with two different types of necks, i.e., HIII and EuroSid-2 dummy. They made impacts in the rear and lateral areas at $3 \mathrm{~m} / \mathrm{s}$, obtaining data related to the maximum longitudinal and rotational accelerations measured at the center of gravity of the head model. The data served as input for a validated simulated injury monitor (SIMon) of the brain for analyzing brain strain. They designed this methodology to analyze the consequence of rotational accelerations on brain damage.

Barlow et al. [22] developed a combined combat helmet design improvement methodology that took into account different parameters such as the size of the foams, the tension of the straps, the impact location, or the impact velocity. This methodology combined a validated finite element model with experimental tests that simulated the combat helmet drop tower tests. From the results, peak linear acceleration was obtained. This parameter was used as input for a statistical model to optimize helmet design.

In 2012, Fitek and Moyes [23] realized an investigation for the Natick Soldier Research, Development and Engineering Centre in which they tested different foam materials and configurations for the design of combat helmets. They developed a finite element model in LS-Dyna, validated previously with experimental test, which combined different foam configurations, and subjected the helmet to different velocity and impact locations.

McEntire and Whitley [24] analyzed the performance of different combat helmets used by the U.S. Army, i.e., the advanced combat helmet (ACH), and Personnel Armor System for Ground Troops (PASGT). Impact series tests were carried out at two impact velocities, three ambient temperatures, and seven different impact locations, and the peak linear acceleration produced from each one was obtained. The results obtained for both helmets were compared with the recommended threshold for maximum acceleration.

In a study carried out by Staniszewski et al. [25], they analyzed the behavior of the ACH at impact velocities higher than those that were validated, i.e., higher than $3 \mathrm{~m} / \mathrm{s}$, whose maximum linear acceleration value was $150 \mathrm{~g}$. Through modifications of the internal damping system and the inner foams, and using a finite element model previously validated with experimental tests, they increased the impact velocity up to $5.2 \mathrm{~m} / \mathrm{s}$, and obtained a linear acceleration peak of less than $150 \mathrm{~g}$.

In this paper, we focus on TBI analysis with the aim of examining combat helmet performance under blunt impacts. The applicable standards for blunt protection can be improved and the surrogate head does not faithfully represent the human head behavior under this type of load. Thus, the following two head models are used: the standard surrogate head, according to the ECE R22.05 standard and a human head model, previously validated for impacts in traffic accidents.

The main contributions of our work to the study of helmets for blunt impacts are as follows: (i) A numerical analysis is carried out using a widely validated model of the human head-neck assembly and adapted to use in simulations under blunt impacts. (ii) The analysis of a current combat helmet on blunt threats has been introduced with injury criteria such as the center of gravity accelerations of the brain and the head injury criterion (HIC). (iii) The severity of injuries produced are directly related to the widely accepted criterion of HIC. (iv) A comparison of injury criteria results is carried out with two head models. 


\section{Materials and Methods}

\subsection{Introduction to the Development of the Numerical Model}

In this study, we developed a finite element model consisting of an evaluation of a combat helmet subjected to low impact velocity and assessing for traumatic brain injury. The protective performance of the helmet was evaluated using an acceleration analysis of parameters such as HIC (head injury criterion).

LS-Dyna Finite element software was used to analyze the combat helmet behavior under low velocity impact. In this section, the different parts of the numerical model (helmet, human head, and head surrogate) are presented. The human head model used in this work had been previously validated by a co-author $[26,27]$.

\subsubsection{Helmet Model}

The combat helmet model used in this work is shown in Figure 1. The helmet model assembly consisted of different parts, i.e., composite structure helmet, foams, and straps. Each part was modeled using CAD software Autodesk Inventor from original dimensions and meshed with Altair Hypermesh 13.0 software which enabled better mesh strategies and techniques.

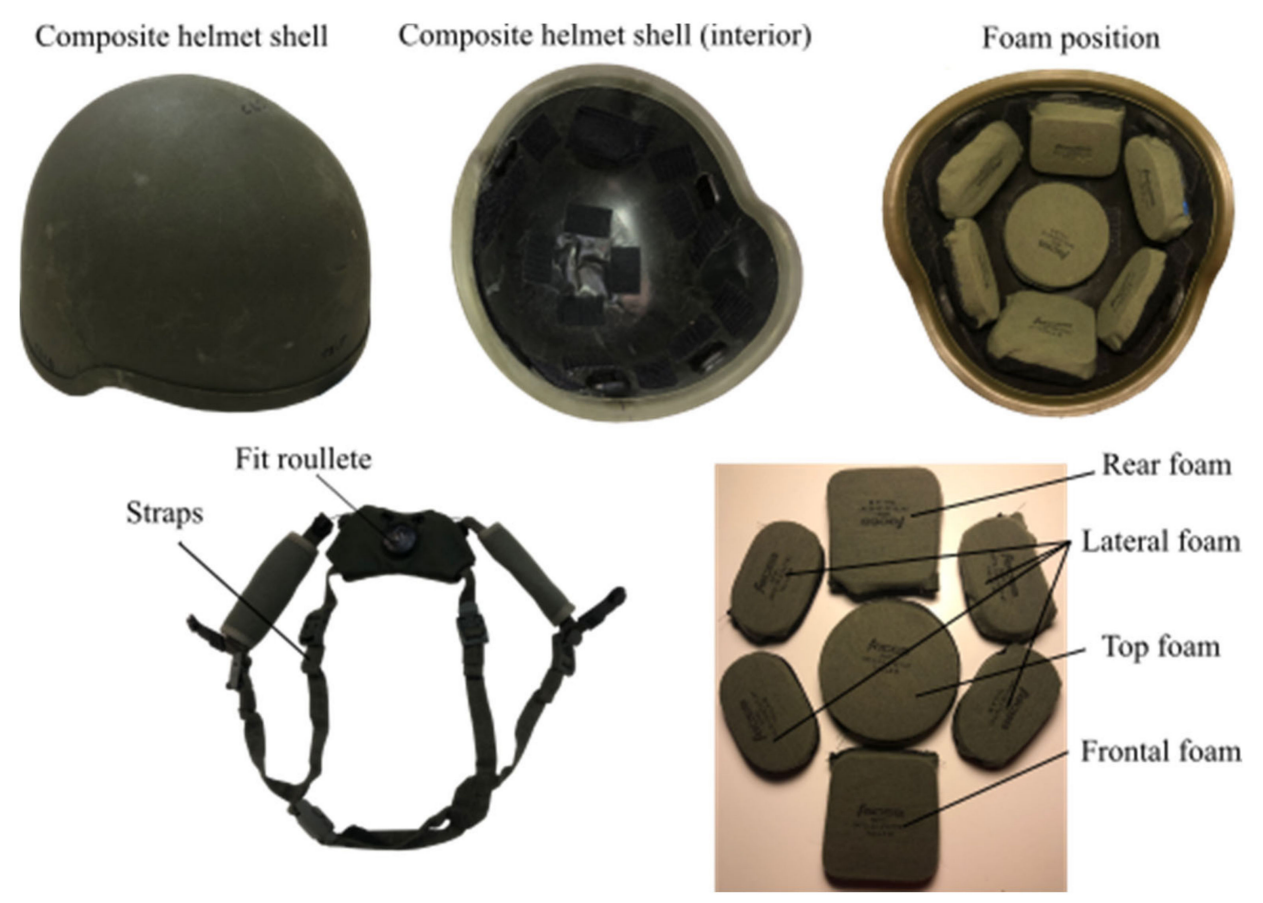

Figure 1. Combat helmet shell, foams, and straps.

The shell is the most external part of the helmet assembly and constitutes the principal protective structure of the combat helmet. It is made of composite aramid fibers with a phenolic matrix, which is widely used in lightweight personal protection manufacturing [10,28-33] due to its high ballistic performance and good resistance and low weight ratio. The shell areal density is $8.86 \mathrm{~kg} / \mathrm{cm}^{2}$.

Due to the heterogeneity and anisotropy of the composite materials, ${ }^{*}$ MAT_COMPOSITE_DAMAGE (MAT_022) was used to define mechanical behavior model of the aramid composite, through an orthotropic material model (9 elastic constants) and it was modeled as linear elastic until failure.

The damage criterion for aramid composite used in this work was modeled using the Chang-Chang model [34,35], which considered the following three principal intralaminar failure modes: fiber breakage, matrix cracking, and matrix compression, i.e., Equations (1)-(3). The direction assignment for the composite material is done in the local coordinate system $(1,2,3)$, where 1 and 2 are the directions 
on lamina plane and 3 is orthogonal to the other directions, out of the lamina plane, through the thickness direction.

The intralaminar failure modes (MAT_022) can be described as follow:

Fiber breakage criterion is defined as:

$$
F_{\text {fiber }}^{2}=\left(\frac{\sigma_{11}}{X_{T}}\right)^{2}+\bar{\tau} ; \sigma_{11}>0
$$

where $X_{t}$ is the tensile strength in the fiber direction (longitudinal) and $\sigma_{11}$ is the normal stress in the same direction.

When the failure criterion of Equation (1) is satisfied, $F_{\text {fibre }} \geq 1$, all elastic constants involved on the failed lamina plane are set to zero, $\left(E_{11}=E_{22}=G_{12}=v_{12}=v_{21}=0\right)$. Failed fibers cannot support loads along the axial (or longitudinal) and shear (transverse) directions, and the load is redirected to the rest of the lamina.

The matrix cracking Equation (2) and matrix compression failure Equation (3) are defined as:

$$
\begin{gathered}
F_{\substack{\text { matrix } \\
\text { crack }}}^{2}=\left(\frac{\sigma_{22}}{Y_{T}}\right)^{2}+\bar{\tau} ; \sigma_{22}>0 \\
F_{\substack{\text { matrix } \\
\text { crack }}}^{2}=\left(\frac{\sigma_{22}}{2 s_{c}}\right)^{2}+\left[\left(\frac{Y_{c}}{2 s_{c}}\right)^{2}-1\right] \frac{\sigma_{22}}{Y_{c}}+\bar{\tau} ; \sigma_{22}<0
\end{gathered}
$$

where $Y_{t}$ is the tensile strength in the 22-dir, $Y_{c}$ is the transverse compressive strength, and $\sigma_{22}$ is the normal stress in that direction. When matrix cracking or matrix compression failure criterion is satisfied, $F_{\text {matrix crack }} \geq 1$ or $F_{\text {matrix comp }} \geq 1$, and all of the elastic constants except elastic modulus in 11 direction $\left(E_{11}\right)$, are set to zero. This resembles that the lamina cannot provide support in the shear directions of the fibers; hence, the corresponding shear modulus is also set to zero.

In addition, the $\bar{\tau}$ parameter is the ratio between shear stress and shear strength as follows:

$$
\bar{\tau}=\frac{\frac{\sigma_{12}^{2}}{2 G_{12}}+\frac{3 \alpha_{1} \sigma_{12}^{4}}{4}}{\frac{S_{c}^{2}}{2 G_{12}}+\frac{3 \alpha_{1} S_{c}^{4}}{4}}
$$

where $G_{12}$ is shear modulus, $S_{c}$ is the longitudinal shear strength, $\sigma_{12}$ is the shear stress, and $\alpha$ is a nonlinear shear stress coefficient $(0<\alpha<0.5)$ for which, in this study, a zero value is assumed.

Finally, since it is a multilayer composite material, a failure criterion has to be defined for the delamination of the layers, which is formulated as follows:

$$
F_{\text {delam }}^{2}=\left(\frac{\max \left(0, \sigma_{3}\right)}{S_{3}}\right)^{2}+\left(\frac{\tau_{23}}{S_{23}}\right)^{2}+\left(\frac{\tau_{31}}{S_{31}}\right)^{2}
$$

where $S_{3}, S_{13}$, and $S_{23}$, are the tensile and shear strength in through thickness direction and $\sigma_{3}, \bar{\tau}_{13}$, and $\bar{\tau}_{23}$ are normal and shear stress in the out-of-lamina-plane direction.

The mechanical properties of aramid composite used for this model are listed in Table 1.

The mechanical behavior model previously described, and the mechanical properties mentioned (in the case of aramid composite components) are widely used in works that analyze the dynamic behavior, generally ballistic, of the type of composite materials used in personal protection.

Another part of the helmet assembly is the straps which are modeled using Hypermesh 13.0 software, through CAD module. This part was designed from previous dimensions of a real model. The helmet was positioned on each head/dummy in the correct position. About these, straps are modeled using surfaces over the external surface of the head/dummy and helmet internal surface. 
Table 1. Mechanical properties of aramid composite used for the helmet shell.

\begin{tabular}{|c|c|c|c|c|c|}
\hline Density & $\rho\left(\mathrm{kg} / \mathrm{m}^{3}\right)$ & 1230 & Shear Modulus Plane 23 & $G_{23}(\mathrm{GPa})$ & 2.5 \\
\hline $\begin{array}{l}\text { Young's modulus } \\
\text { direction } 11\end{array}$ & $E_{1}(\mathrm{GPa})$ & 18.5 & Tensile strength direction 11 & $X_{t}(\mathrm{GPa})$ & 0.555 \\
\hline $\begin{array}{l}\text { Young's modulus } \\
\text { direction } 22\end{array}$ & $E_{2}(\mathrm{GPa})$ & 18.5 & Tensile strength direction 22 & $Y_{t}(\mathrm{GPa})$ & 0.555 \\
\hline $\begin{array}{l}\text { Young's modulus } \\
\text { direction } 33\end{array}$ & $E_{3}(\mathrm{GPa})$ & 6 & Shear Strength plane 12 & $S_{c}(\mathrm{GPa} 0$ & 0.588 \\
\hline Poisson's ratio plane 12 & $\vee 12(-)$ & 0.25 & Compressive strength direction 22 & $Y_{c}(\mathrm{GPa})$ & 1.086 \\
\hline Poisson's ratio plane 13 & $v 13(-)$ & 0.33 & Normal tensile strength & $S_{n}(\mathrm{GPa})$ & 0.835 \\
\hline Poisson's ratio plane 23 & $v 23(-)$ & 0.33 & Transverse shear strength & $S_{13}(\mathrm{GPa})$ & 1.06 \\
\hline Shear modulus plane 12 & $\mathrm{G}_{12}(\mathrm{GPa} 0$ & 0.77 & Transverse shear strength & $S_{23}(\mathrm{GPa})$ & 1.06 \\
\hline Shear modulus plane 13 & $\mathrm{G}_{13}(\mathrm{~Pa})$ & 2.5 & & & \\
\hline
\end{tabular}

The mechanical behavior of the straps was modeled as linear elastic behavior (MAT_ELASTIC) with the following mechanical properties: $1400 \mathrm{~kg} / \mathrm{m}^{3}$ for the density, $1000 \mathrm{MPa}$ for the elastic modulus, and 0.44 for the Poisson coefficient.

The pad suspensions were made up of two components, i.e., a hard foam to absorb impact energy and a softer foam whose function was to provide comfort to the wearer. These parts were modeled in CAD and exported to Hypermesh software to mesh, see Figure 2. The total thickness of each foam pad was $21 \mathrm{~mm}$. Three different foam pads were modeled, due to frontal and rear foams and the four lateral foam pads were the same. The top foam pad differed from the two others.
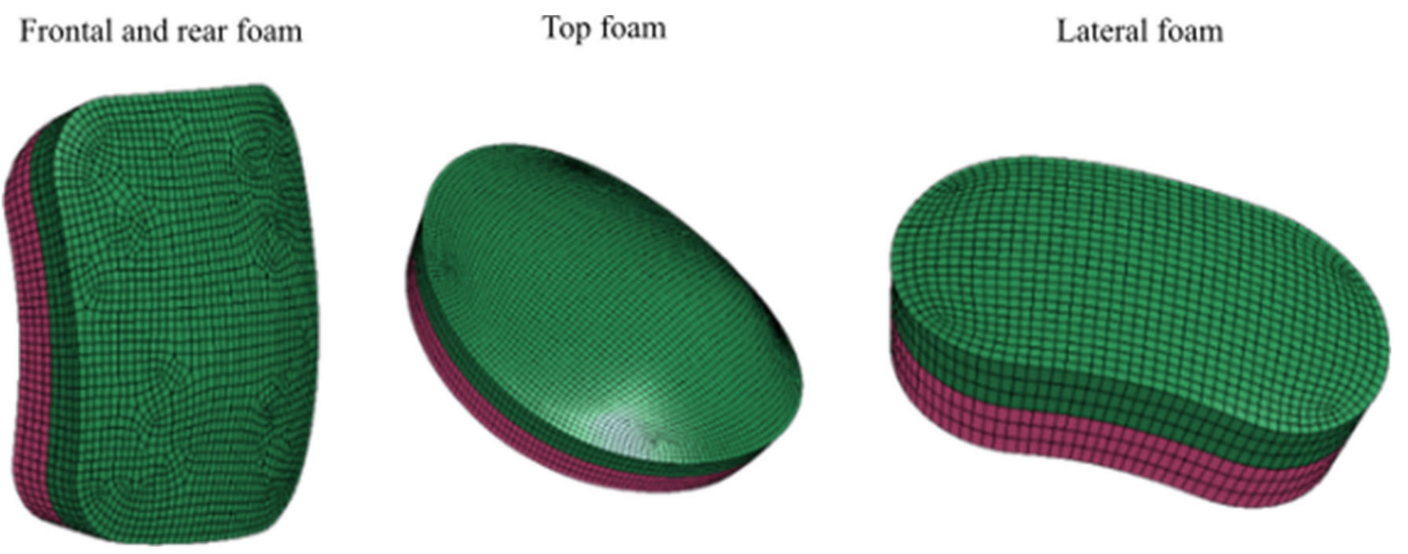

Figure 2. Finite element model of foam pads. (deformed).

It is important to mention that these types of foams are manufactured in such a way a single part is formed where each trough thickness half corresponds to hard foam and soft foam. For this model, the foams were modeled like a single solid, and each half was assigned equivalent foam properties.

The mechanical behavior of each component polyurethane foam was modeled using the MAT_LOW_DENSITY_FOAM option for low-density elastomeric foams with high compressibility. Table 2 shows the mechanical properties of both foams [14,36,37].

Moreover, polyurethane foam has a high sensitivity to strain ratio, and yield stress also varies with this parameter. Experimental compression tests on both types of foams, up to a strain rate of $50 \mathrm{~s}^{-1}$, are found in the literature [34]. However, polyurethane foams are subjected to higher strain rates on impact events. For this reason, the stress-strain curves from low strain rate up to higher strain rates levels were extrapolated. Li et al. [37] extrapolated the curves from 2 to $2500 \mathrm{~s}^{-1}$, as is shown in Figure 3. 
Table 2. Mechanical properties of foams obtained from [14,36,37].

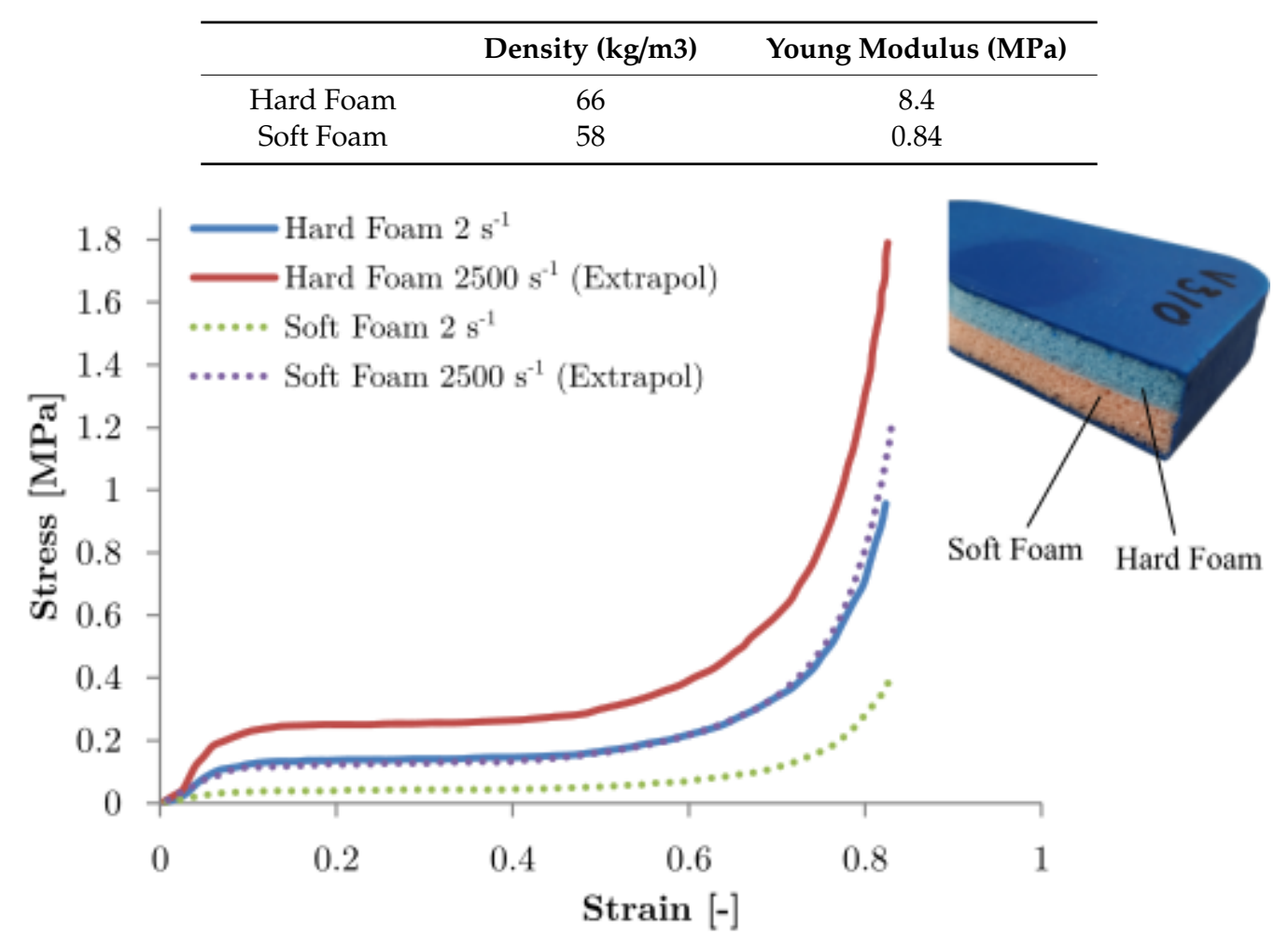

Figure 3. Stress-strain curves for both inner foams.

The geometrical model of the shell was meshed using 110,440 hexahedral of 8-node elements with reduced integration and, 8 elements through thickness. The foams pads were also meshed with hexahedral 8-node elements. The rear and front foam pads were created using 12,688 elements, each lateral foam pad had 5832 elements, and the top foam pad was meshed with 21,456 elements. Six elements through thickness were used for the mesh of the foam pads. The straps were modeled using 1912 hexahedral elements of 8-node with reduced integration.

\subsubsection{Human Head Model}

The human head numerical model used in this study was developed by a co-author, Dr. J. Antona-Makoshi [27], and was validated through different impact events with high probability to occur in a traffic accident, inducing cerebral injuries. The numerical model of the human head was obtained by computerized tomography (CT) and magnetic resonance imaging (MRI).

The complete head is a compound of multiple parts to reproduce, with high realism, a real human head, i.e., scalp, white and grey matter brain, corpus callosum, falx cerebri, are some of the elements that are distinguished in the numerical model. In addition, one part of the human neck is defined with $\mathrm{C} 1$ to $\mathrm{C} 7$ vertebrae and their respective intervertebral disks and ligaments.

The total mass of the human head model is $6.47 \mathrm{~kg}$. Figure 4 shows the numerical model of the complete head with details of internal parts. It is important to mention that the head assembly is modeled symmetrically with respect to the sagittal plane.

The mechanical proprieties of the human head model are summarized in Table 3 [27].

The human head mesh is created using 291,948 solid elements and 53,609 shell elements. For further details of the human model see the doctoral thesis of Dr. Antona-Makoshi [27]. 


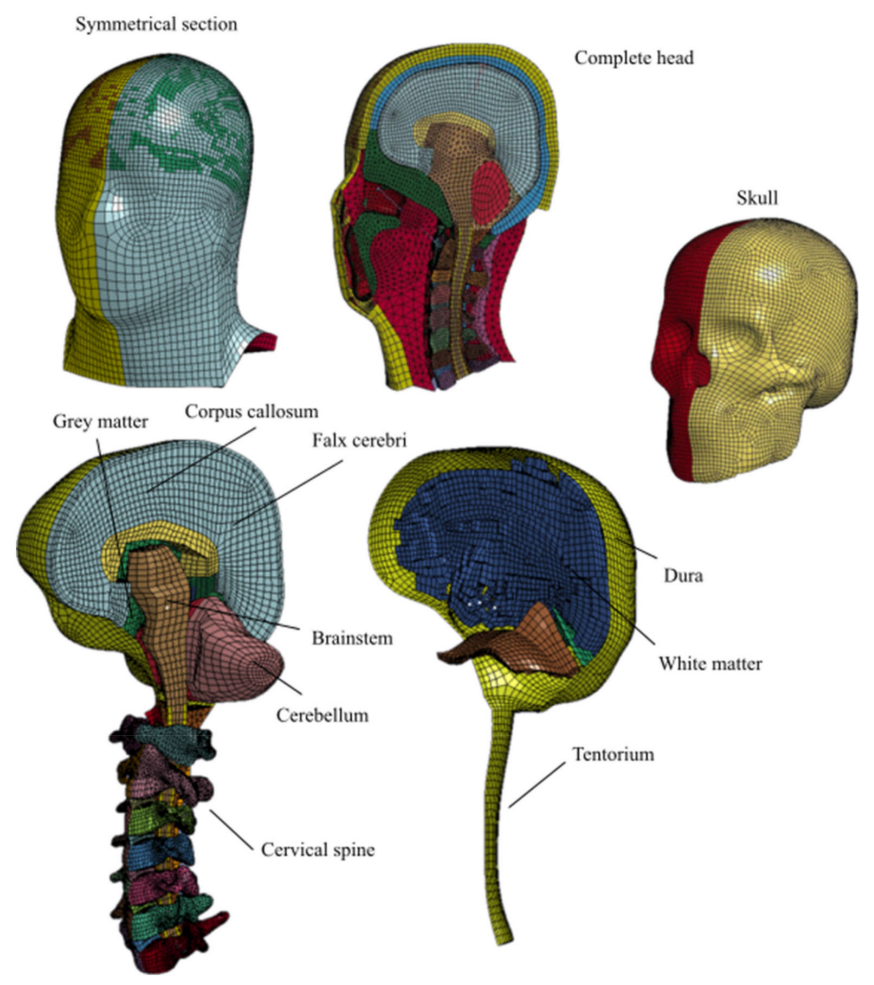

Figure 4. Human head model (6.47 kg mass).

Table 3. Human head mechanical properties.

\begin{tabular}{|c|c|c|c|}
\hline & Material Model LS-Dyna & Material Properties & Author \\
\hline $\begin{array}{l}\text { Scalp and neck } \\
\text { flesh }\end{array}$ & Fu Chang foam & $\begin{array}{l}\text { Stress-strain curves } \\
\text { at } 3 \text { strain rates }\end{array}$ & $\begin{array}{l}\text { Human cadaver Ssalp in } \\
\text { compression, McElhaney [38] }\end{array}$ \\
\hline Skull tables & Piecewise linear plasticity & $\mathrm{E}=6.48 \mathrm{GPa}$ & $\begin{array}{l}\text { Human skull tables in shear, } \\
\text { McElhaney [38] }\end{array}$ \\
\hline Skull diploe & Isotropic elastic plastic & $\mathrm{E}=40 \mathrm{MPa}$ & McElhaney [38] \\
\hline Dura mater & Elastic & $\mathrm{E}=40 \mathrm{MPa}$ & $\begin{array}{l}\text { Human dura in tension } \\
\text { melvin [39] }\end{array}$ \\
\hline Pia mater & Elastic & $\mathrm{E}=12.5 \mathrm{MPa}$ & $\begin{array}{l}\text { Bovine pia-arachnoid in } \\
\text { shear [40] }\end{array}$ \\
\hline $\begin{array}{l}\text { Cerebrospinal } \\
\text { fluid (CSF) }\end{array}$ & Elastic fluid & $\begin{array}{c}\mathrm{K}=2.1 \mathrm{GPa} \\
v=0.4999\end{array}$ & McElhaney [38] \\
\hline \multirow{2}{*}{ Brain } & Brain linear & $\mathrm{G} 0=1.6 \mathrm{kPa}$ & Porcine brain tissue in shear \\
\hline & Viscoelastic & $\mathrm{G} 1=0.9 \mathrm{kPa}$ & Arbogast and Margulies [41] \\
\hline Falx and tentorium & Elastic & $\mathrm{E}=12.5 \mathrm{MPa}$ & Jin et al. [40] \\
\hline Vertebrae & Rigid & - & - \\
\hline $\begin{array}{l}\text { Intervertebral discs } \\
\text { and facet ioints }\end{array}$ & Elastic & $\mathrm{E}=10 \mathrm{MPa}$ & Brolin et al. [42] \\
\hline Neck ligaments & Elastic & $\mathrm{E}=43.8 \mathrm{MPa}$ & Yoganandan [43] \\
\hline
\end{tabular}

\subsubsection{Head Surrogate Model}

A head surrogate is typically used for helmet certification tests. The surrogate was designed according to the European Standard ECE R22.05. The head surrogate model chosen was size "J" with $57 \mathrm{~cm}$ parietal circumference and $4.7 \mathrm{~kg}$ mass. The principal aim for choosing this dummy head was because it is one of the most important used for helmet certification tests, and therefore developing a numerical model capable of reproducing this type of test, extrapolated to any type of protective helmet, would be very useful for manufacturing companies by reducing logistics costs. The numerical results were compared with experimental tests, as described in the Results section. The surrogate was 
modeled as a rigid solid, since no deformations were observed on it during the experimental tests. The inertial parameters of the surrogate are listed in Table 4 . Figure 5 shows the CAD and the FEM model of the head surrogate.

Table 4. Head surrogate inertial parameters.

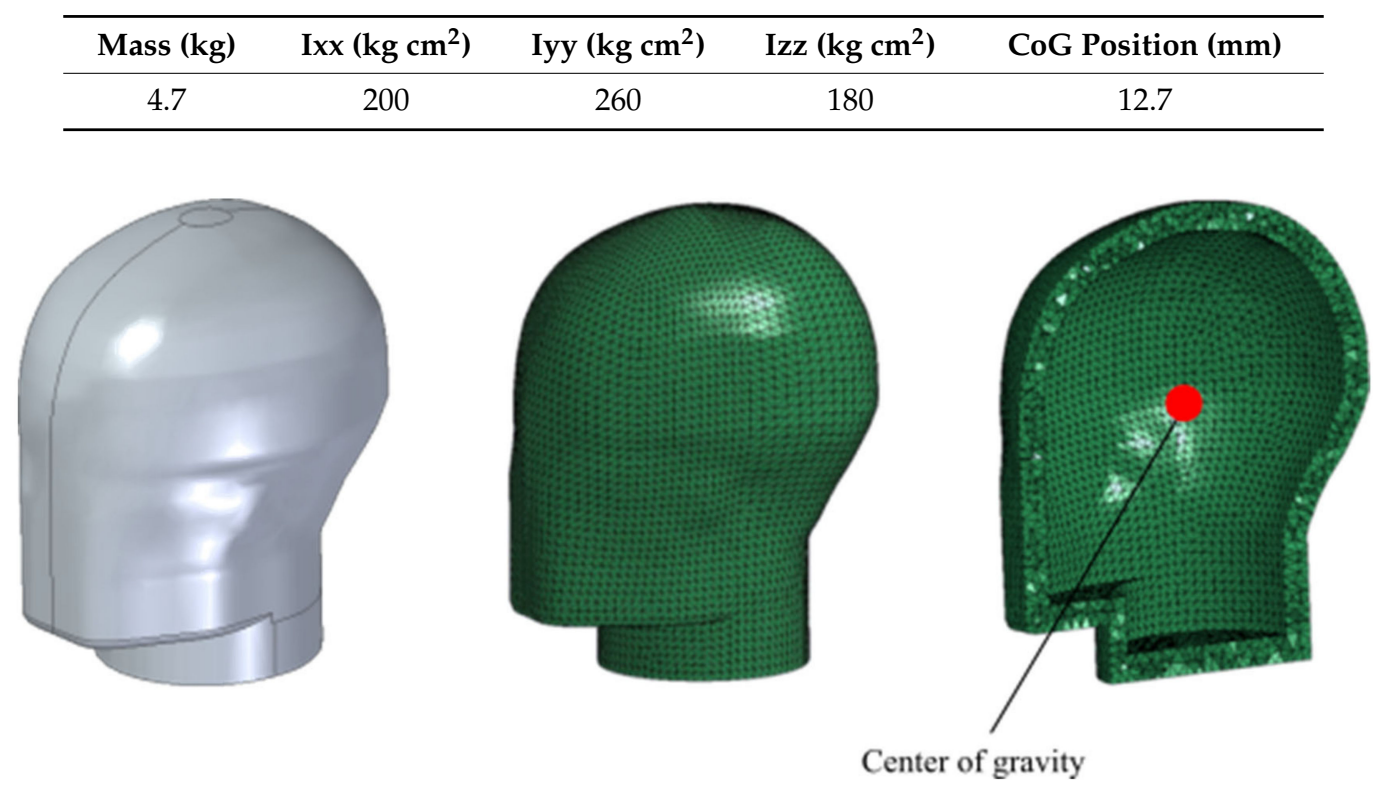

Figure 5. The head surrogate according to the ECE R22.05 standard, size J, and $4.7 \mathrm{~kg}$ mass.

\subsubsection{Helmet and Heads Assembly}

The undeformed foam pads were positioned between the helmet and each head/surrogate and, additionally, they were separated by a determined distance. A quasi-static displacement for the human head or the head surrogate and the helmet was defined to get back into their final positions. During this process, the foam pads were deformed and adapted to the helmet and head. Finally, the straps modeled onto the final stage (previous of impact) were included.

\subsubsection{Interactions and Boundary Conditions for Drop Impact Model}

The contact between the interior shell, the pads, and the straps were defined as TIED_SURFACE_TO_SURFACE. However, the *CONTACT_AUTOMATIC_SURFACE_TO_SURFACE function with a friction coefficient of 0.2 was defined for the contact between the helmet assembly and human head or head surrogate.

An initial impact velocity of $4.4 \mathrm{~m} / \mathrm{s}$ was defined on each model studied (heads and helmet) according to the European Standard ECE R22.05. All degrees of freedom of nodes of the dummy neck base and the human head were restricted, except the movement on drop direction. In addition, a gravity load of $9.81 \mathrm{~m} / \mathrm{s}^{2}$ was defined for the whole model and the accelerations are obtained from center of gravity, Figure 6. The flat anvil was modeled as a rigid solid, and all degrees of freedom were restricted. The flat anvil mesh was created using 125,000 hexahedral elements.

The influence of geometry on the impact surface was analyzed. Two impact surfaces were used, i.e., flat and curbstone anvils. The dimensions of the curbstone anvil were $125 \mathrm{~mm}$ length and $52^{\circ}$ of angle faces which were joined at a fillet radius of $15 \mathrm{~mm}$. The height was $50 \mathrm{~mm}$. It was modeled as a rigid solid since it was assumed that it would not undergo deformations during the impact process. The curbstone anvil was meshed with 22,050 hexahedral elements. Figure 7 shows the curbstone anvil geometry and the mesh, and Figure 8 illustrates the different configurations for the two head models. 

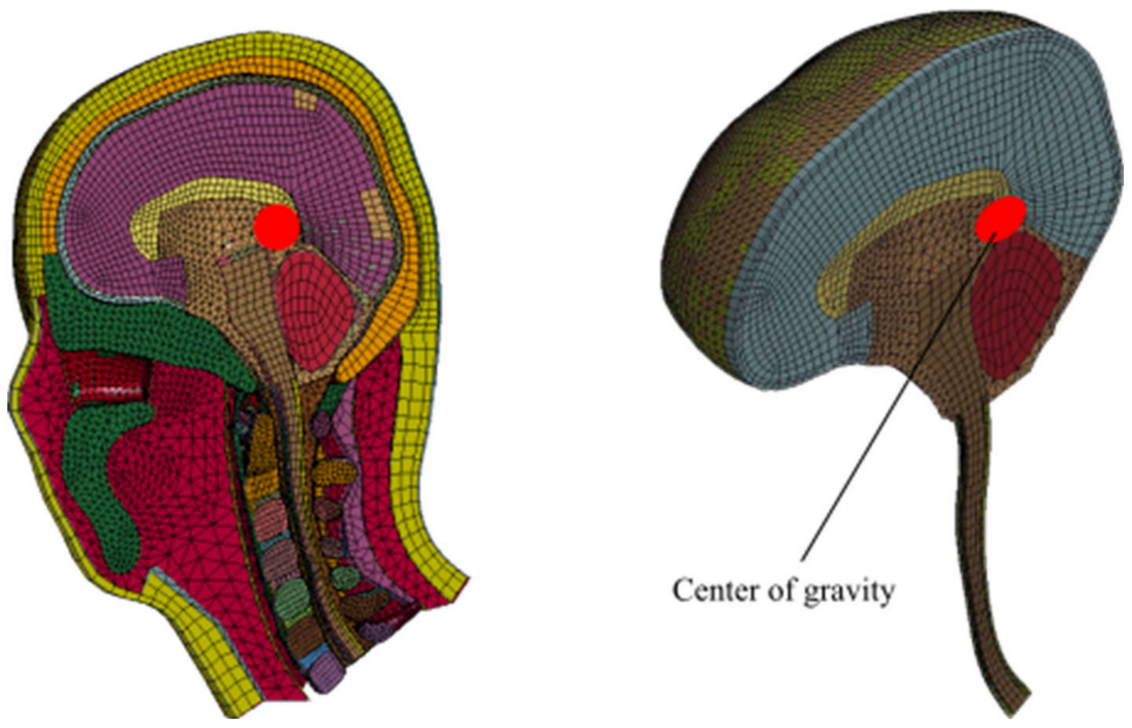

Figure 6. Center of gravity of human head model.

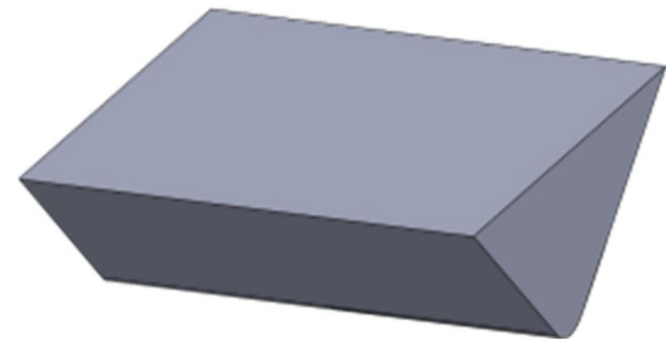

(a)

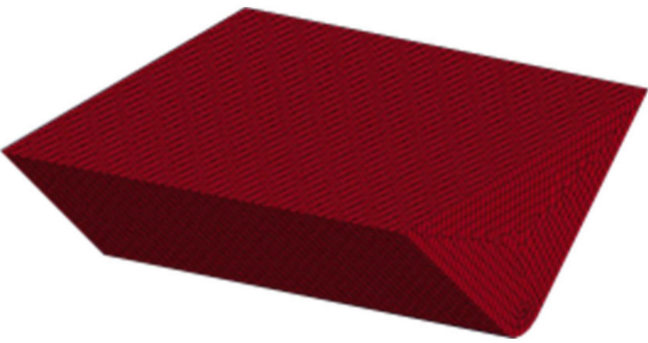

(b)

Figure 7. Curbstone anvil model used for impact surface analysis. (a) CAD model; (b) FEM model.

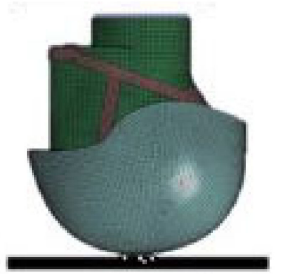

Top impact

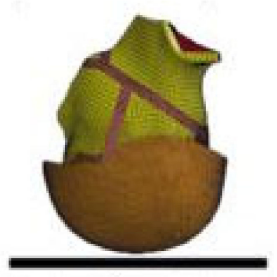

Top impact

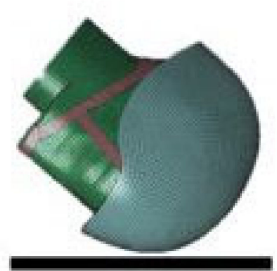

Frontal impact

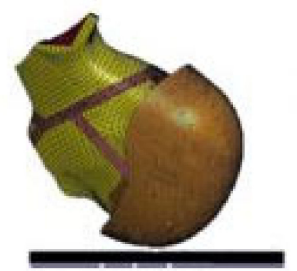

Frontal impact

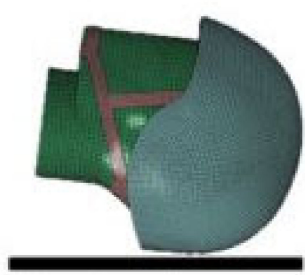

Rear impact

(a)

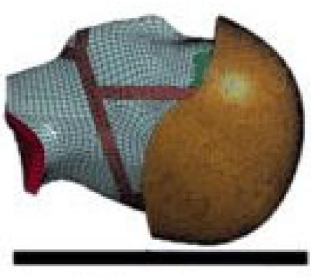

Rear impact

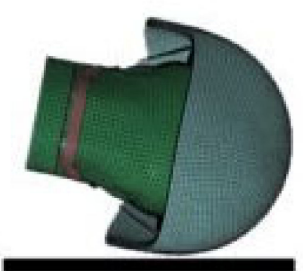

Lateral impact

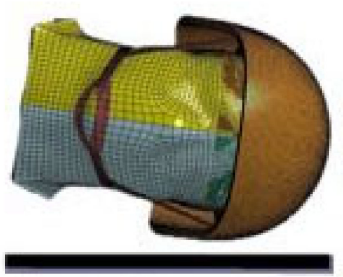

Lateral impact

(b)

Figure 8. The different configurations for the head models: (a) Head surrogate; (b) Human head. 


\subsection{Injury Predictors}

\subsubsection{Peak Linear Acceleration (PLA)}

The maximum peak linear acceleration (PLA) is a method used to evaluate the brain injury criterion. According to the ECE R22/05 standard, a PLA over $275 \mathrm{~g}$ indicates serious injuries.

The relationship between PLA and mild brain injury is evaluated by the expression, Equation (6), according to the COST 327, Motorcycle Safety Helmets report by the European Commission [44]:

$$
\text { AIS Head }=1.7426 \ln P L A-6.7228
$$

\subsubsection{Head Injury Criterion (HIC)}

One of the most used criteria for determining brain injuries due to impact events is the head injury criterion (HIC). The expression to obtain HIC value is as follows:

$$
H I C=\left\{\left[\frac{1}{t_{2}-t_{1}} \int_{t_{1}}^{t_{2}} a(t) d t\right]^{2,5}\left(t_{2}-t_{1}\right)\right\}_{\max }
$$

where $t_{1}$ and $t_{2}$ are the interval time, where HIC is maximum, and a(t) is measured in $\mathrm{g}^{\prime} \mathrm{s}$, and the direction impact acceleration history is calculating on center of gravity. The threshold HIC used in this work was 1000 according to the NHTSA (National Highway Traffic Safety Administration) [43] and 2400 established by the European Standard ECE R22/05 [19].

\subsubsection{Injury Risk Curve}

Hayes et al. [41] showed the probability of different injury modes based on HIC values, as explained in Table 5.

Table 5. Explanation of severity code by Hayes et al. [41].

\begin{tabular}{ccc}
\hline AIS CODE & Severity Code & Fatality Rate (Range \%) \\
\hline 1 & Minor & 0.0 \\
2 & Moderate & $0.1-0.4$ \\
3 & Serious & $0.8-2.1$ \\
4 & Severe & $7.9-10.6$ \\
5 & Critical & $53.1-58.4$ \\
6 & Maximum & Untreatable \\
\hline
\end{tabular}

The HIC value is associated with a level of damage in the AIS scale presented above. Wilson et al. [44] defined risk curves where the likelihood of suffering brain injuries was related to the HIC for each one of six levels of the AIS scale, Figure 9. 


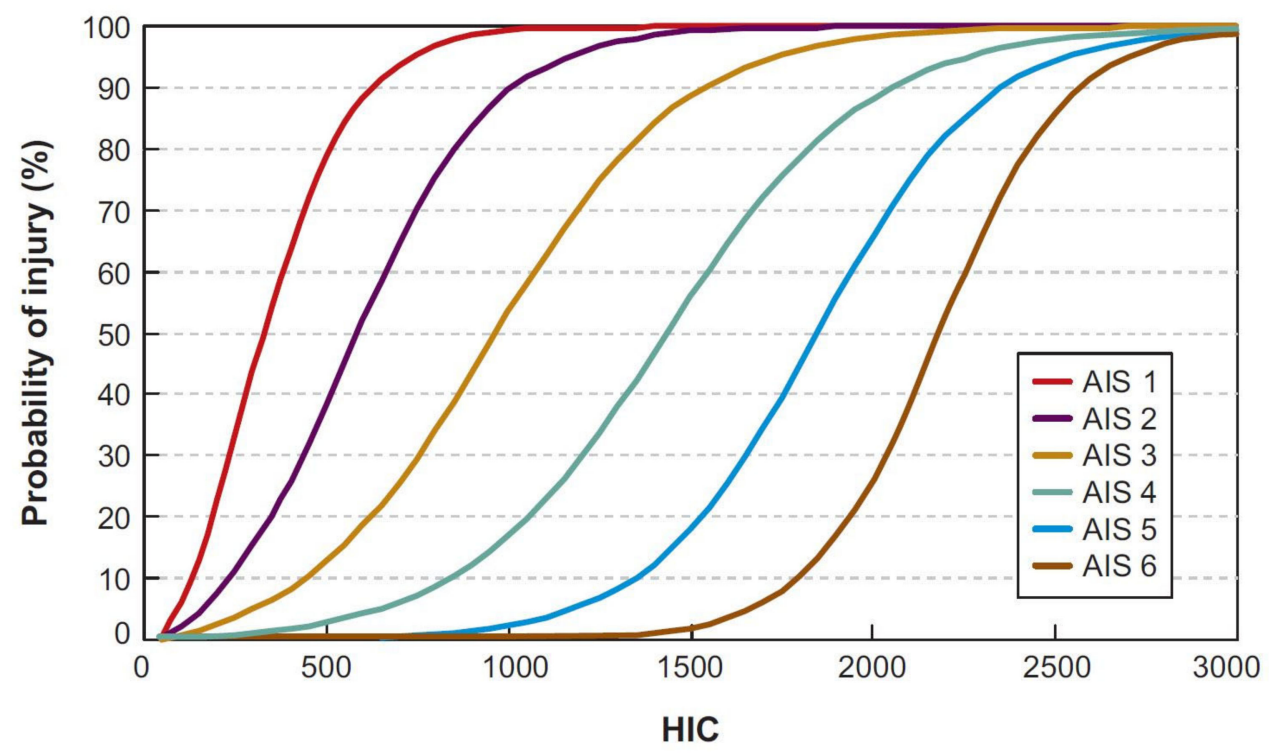

Figure 9. Head injury risk curves, according to the AIS scale, based on the head injury criterion (HIC).

\section{Results}

In this section, the protective performance of a combat helmet is evaluated using the two head models carried out on the following different impact locations: front, lateral, top, and rear. The peak linear accelerations and the HIC (head injury criteria) value are obtained for each impact location and head in order to analyze traumatic brain injury (TBI).

For the head form, the acceleration is measured at its center of gravity; while, in the human head, the measurement is obtained from a set of parts, at its center of gravity, i.e., grey and white matter, corpus callosum, falx, cerebri, tentorium, cerebrospinal fluid and dura mater (Figure 6).

To supplement our study, two anvils are used, and the drop velocity is varied to analyze the influence on the protective performance of the combat helmet.

\subsection{Flat Anvil Surface}

\subsubsection{Peak Linear Acceleration (PLA)}

For each location and head used, Figure 10 shows the linear acceleration history, where the maximum peak linear acceleration can be measured.

Using the expression for induced damage due to impact, previously described as Equation (6), an analysis of the AIS scale is realized for each case. Table 6 shows the values obtained for peak linear acceleration and AIS.

For the head form configuration, no PLA value exceeds the threshold of $275 \mathrm{~g}$ set by the standards. All AIS values are around three; consequently, the degree of brain injury is serious severity, and loss of consciousness, between 1 and $6 \mathrm{~h}$, appears. For the human head model, the PLA value is over the established limit (293 $>275 \mathrm{~g})$, causing a situation of high risk for individuals wearing ballistic protective helmets.

It follows that the results obtained from the configurations are compared in terms of PLA with data provided by the combat helmet manufacturer and ACH military combat helmet used by Fitek and Meyer [23]. All the tests were carried out according to the ECE R22.05 standard and an impact velocity of $4.4 \mathrm{~m} / \mathrm{s}$. 


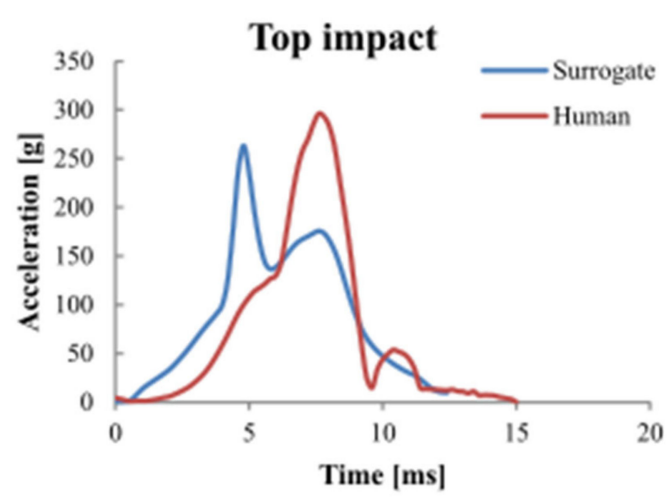

(a)

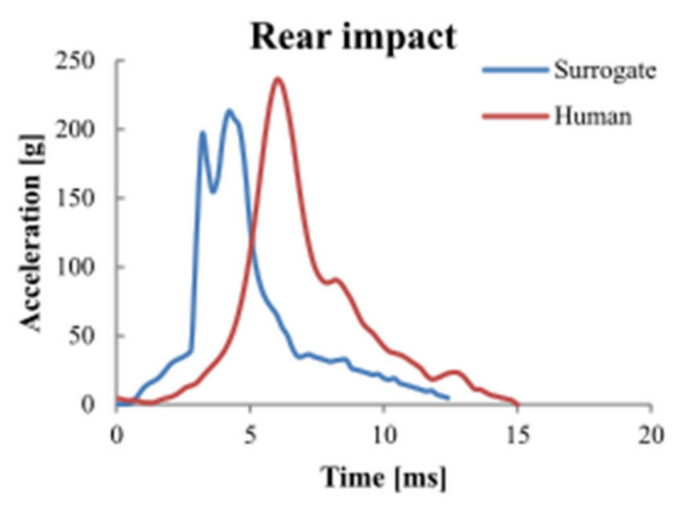

(c)

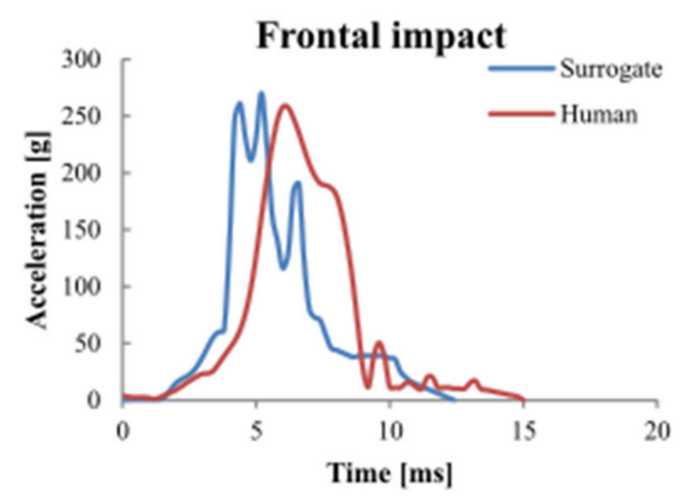

(b)

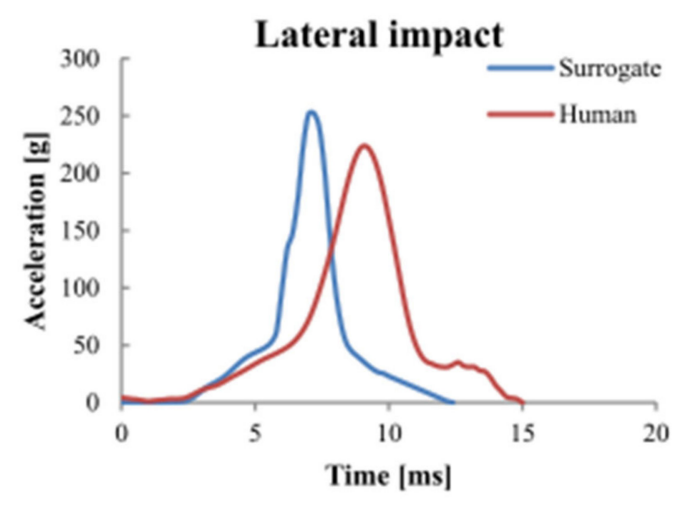

(d)

Figure 10. The acceleration evolution comparison of both head models used for each impact location. (a) Top impact; (b) Frontal impact; (c) Rear impact; (d) Lateral impact.

Table 6. Results for an impact velocity of $4.4 \mathrm{~m} / \mathrm{s}$ for the head surrogate and the human head.

\begin{tabular}{|c|c|c|c|c|c|}
\hline Head Model & Location & PLA (g) & $<275 \mathrm{~g}$ & $\begin{array}{c}\text { AIS head } \\
\text { (Equation (6)) }\end{array}$ & AIS Scale \\
\hline \multirow{4}{*}{ Head surrogate } & Top & 263 & yes & 2.99 & \multirow{4}{*}{$\begin{array}{c}3 \\
3 \\
2 \text { with a } 61 \% \text { of probability } \\
\text { to produces level } 3 \\
3\end{array}$} \\
\hline & Frontal & 270 & yes & 3.03 & \\
\hline & Rear & 210 & Yes & 2.61 & \\
\hline & Lateral & 252 & yes & 2.91 & \\
\hline \multirow{4}{*}{ Human head } & Top & 293 & No & 3.18 & \multirow{4}{*}{$\begin{array}{c}3 \\
3 \\
2 \text { with } 80 \% \text { of probability } \\
\text { to produces level } 3 \\
2 \text { with a } 70 \% \text { of probability } \\
\text { to produces level } 3\end{array}$} \\
\hline & Frontal & 258 & Yes & 2.95 & \\
\hline & Rear & 236 & Yes & 2.8 & \\
\hline & Lateral & 223 & Yes & 2.7 & \\
\hline
\end{tabular}

\subsubsection{Head Injury Criterion (HIC)}

The results for the different configurations are summarized in Table 7. The maximum HIC is 1245 in the frontal zone, whereas the minimum HIC is 868 for rear impacts according to the NHTSA criteria, the HIC threshold is 1000. Therefore, the only configuration that overcomes the limit value is in the frontal impact leading to severe injuries. However, all values are lower than the European Standard, EC ER22/05, in which the HIC threshold is 2400. 
Table 7. HIC and AIS results.

\begin{tabular}{ccccccccc}
\hline Head Model & Location & HIC & $\begin{array}{c}\text { AIS 1 } \\
(\mathbf{\%})\end{array}$ & $\begin{array}{c}\text { AIS 2 } \\
\mathbf{( \% )}\end{array}$ & $\begin{array}{c}\text { AIS 3 } \\
\mathbf{( \% )}\end{array}$ & $\begin{array}{c}\text { AIS 4 } \\
\mathbf{( \% )}\end{array}$ & $\begin{array}{c}\text { AIS 5 } \\
(\mathbf{\%})\end{array}$ & $\begin{array}{c}\text { AIS 6 } \\
(\mathbf{\%})\end{array}$ \\
\hline \multirow{3}{*}{ Head } & Top & 981 & 100 & 90 & 55 & 18 & 3 & 0 \\
surrogate & Frontal & 1245 & 100 & 96 & 77 & 33 & 7 & 0 \\
& Rear & 868 & 98 & 83 & 42 & 11 & 0 & 0 \\
& Lateral & 941 & 99 & 88 & 50 & 12 & 2 & 0 \\
\hline \multirow{3}{*}{ Human } & Top & 2198 & 100 & 100 & 98 & 94 & 82 & 50 \\
Head & Frontal & 2017 & 100 & 100 & 97 & 90 & 70 & 28 \\
& Rear & 995 & 100 & 91 & 56 & 19 & 4 & 0 \\
& Lateral & 1173 & 100 & 95 & 70 & 30 & 5 & 0 \\
\hline
\end{tabular}

For the human head configurations, the maximum HIC is reached at the top location, i.e., HIC $=2198$, and the minimum $\mathrm{HIC}$ is located in the rear zone, i.e., $\mathrm{HIC}=995$. No serious injuries are found for rear impact according to NHTSA. Nevertheless, for the other zone, the severity of injuries can be caused. According to the EC ER22/05 standard, all the results are within the ranges allowed for this standard.

The risk curves for both configurations are defined to relate the HIC value to the AIS level, according to Willson et al. [44], and are shown in Table 7. According to our results, for all locations with the head surrogate, a high probability of level 1 and 2 injuries is achieved. However, the probability of AIS $\geq 3$ is reduced by approximately $50 \%$ for all locations, except for the case of front impact, where the probability is $77 \%$. The worst-case impact is found in the top localization since the probability of AIS 6 is $50 \%$. AIS 6 is associated with the death of an individual.

\subsection{Curbstone Anvil Surface}

The impact velocity is $4.4 \mathrm{~m} / \mathrm{s}$. The impacts on the head surrogate and human head for the different locations are analyzed. The PLA and HIC parameters are analyzed.

\subsubsection{Peak Linear Acceleration (PLA)}

The peak linear accelerations obtained from all cases studied are below the threshold value of $275 \mathrm{~g}$ defined in the ECE R22/05 standard, as shown in Table 8. The worst case is at the top impact if the human head model is used, since it is close to the threshold. However, an AIS 3 level is obtained; consequently, non-fatal injury is caused according to this criterion.

Table 8. Peak linear acceleration (PLA) and AIS for the curbstone anvil case.

\begin{tabular}{|c|c|c|c|c|c|}
\hline Head Model & Location & PLA & $<275 \mathrm{~g}$ & $\begin{array}{c}\text { AIS head } \\
\text { (Equation (6)) }\end{array}$ & AIS level \\
\hline \multirow{4}{*}{$\begin{array}{c}\text { Head } \\
\text { surrogate }\end{array}$} & Top & 270 & Yes & 3.03 & \multirow{4}{*}{$\begin{array}{c}3 \\
3 \\
2 \text { with high probability to } \\
\text { reach level } 3(80 \%) \\
3\end{array}$} \\
\hline & Frontal & 289 & No & 3.15 & \\
\hline & Rear & 236 & Yes & 2.8 & \\
\hline & Lateral & 267 & Yes & 3.01 & \\
\hline \multirow{4}{*}{ Human head } & Top & 274 & Yes & 3.05 & \multirow{4}{*}{$\begin{array}{c}3 \\
2 \text { with high probability to } \\
\text { reach level } 3(80 \%) \\
2 \text { with high probability to } \\
\text { reach level 3 }(80 \%) \\
2 \text { with probability to reach } \\
\text { level 3 }(50 \%)\end{array}$} \\
\hline & Frontal & 245 & Yes & 2.9 & \\
\hline & Rear & 229 & Yes & 2.8 & \\
\hline & Lateral & 202 & Yes & 2.5 & \\
\hline
\end{tabular}

\subsubsection{Head Injury Criterion (HIC)}

For the head surrogate, the maximum HIC values obtained for the lateral, rear, and top impacts are lower than the threshold established by the NHTSA standard (HIC = 1000), Table 9. In the case of 
frontal impacts, this parameter is very close to the threshold. In the human head configuration, all the cases are higher than HIC $=1000$, and therefore severe injuries may be caused. However, all HIC values for both configurations do not exceed the maximum threshold, $\mathrm{HIC}=2400$, allowed by the ECE R22/05 standard.

Table 9. HIC and AIS (\%) for curbstone anvil case.

\begin{tabular}{ccccccccc}
\hline Head Model & Location & HIC & $\begin{array}{c}\text { AIS 1 } \\
\mathbf{( \% )}\end{array}$ & $\begin{array}{c}\text { AIS 2 } \\
(\mathbf{\%})\end{array}$ & $\begin{array}{c}\text { AIS 3 } \\
(\mathbf{\%})\end{array}$ & $\begin{array}{c}\text { AIS 4 } \\
(\mathbf{\%})\end{array}$ & $\begin{array}{c}\text { AIS 5 } \\
(\mathbf{\%})\end{array}$ & $\begin{array}{c}\text { AIS 6 } \\
(\mathbf{\%})\end{array}$ \\
\hline \multirow{3}{*}{ Head } & Top & 818 & 97 & 77 & 36 & 10 & 0 & 0 \\
surrogate & Frontal & 1066 & 100 & 90 & 55 & 18 & 2 & 0 \\
& Rear & 502 & 80 & 40 & 12 & 3 & 0 & 0 \\
& Lateral & 620 & 90 & 55 & 20 & 5 & 0 & 0 \\
\hline \multirow{2}{*}{ Human } & Top & 1695 & 100 & 100 & 95 & 72 & 33 & 7 \\
head & Frontal & 2025 & 100 & 100 & 98 & 90 & 70 & 30 \\
& Rear & 1584 & 100 & 100 & 91 & 62 & 22 & 4 \\
& Lateral & 1038 & 100 & 91 & 57 & 19 & 2 & 0 \\
\hline
\end{tabular}

The results obtained with both models also show high probabilities for causing injuries from the AIS 1 level to the AIS 2 level. For the head surrogate configurations, the probability of suffering traumatic brain injuries is significantly reduced; however, there may be significant potential for causing traumatic brain injury at the AIS 4 level and even at the AIS 5 level.

\subsection{Influence of Impact Velocity}

The influence of impact velocity is analyzed in this section using the flat anvil. The impact velocity is reduced to $3,3.5$, and $3.9 \mathrm{~m} / \mathrm{s}$, since it is assumed that with higher velocities, more severe injuries are induced than in the previous sections.

\section{Peak Linear Acceleration (PLA)}

The main consequence of reducing the impact velocity is the decrease in the risk of suffering serious injuries. Table 10 shows the injuries according to the AIS scale. All the cases are below the AIS 1 and 2 levels. As described above, the probabilities of obtaining AIS $\geq 3$ are greater than $50 \%$ for impact velocities of $4.4 \mathrm{~m} / \mathrm{s}$ for all configurations, as shown in Table 6 . Therefore, impact velocity is a critical factor in traumatic brain injuries by blunt impact at low impact velocities

Table 10. PLA and AIS for impact velocity $\mathrm{v}_{0}=3 \mathrm{~m} / \mathrm{s}$.

\begin{tabular}{ccccc}
\hline Head Model & $\begin{array}{c}\text { Impact Velocity } \\
(\mathbf{m} / \mathbf{s})\end{array}$ & PLA & $\begin{array}{c}\text { AIS Head } \\
\text { (Equation (6)) }\end{array}$ & AIS Level \\
\hline 3 & 147 & 1.97 & $\begin{array}{c}2 \\
\text { Head surrogate }\end{array}$ \\
3.5 & 195 & 2.5 & $\begin{array}{c}\text { with a 50\% of probability to } \\
\text { produces level 3 }\end{array}$ \\
& 3.9 & 217 & 2.65 & 2 with a 65\% of probability to \\
produces level 3 \\
Human head
\end{tabular}

Analysis of traumatic brain injury, according to AIS, is shown in Table 11 for the different impact velocities. As mentioned above, a reduction in the impact velocity leads to a decrease in the parameter 
values. For impact velocities below $3.5 \mathrm{~m} / \mathrm{s}$, the values are well within safe limits and, consequently, involve a reduction in the risk of suffering serious injuries according to standards ECE R22/05 [19] and NHTSA [43]. Thus, the probability of causing traumatic brain injuries according to AIS 3 is considerably low.

Table 11. HIC and AIS (\%) for different impact velocities.

\begin{tabular}{ccccccccc}
\hline Head Model & $\begin{array}{c}\text { Impact Velocity } \\
(\mathbf{m} / \mathbf{s})\end{array}$ & HIC & $\begin{array}{c}\text { AIS 1 } \\
(\mathbf{\%})\end{array}$ & $\begin{array}{c}\text { AIS 2 } \\
(\%)\end{array}$ & $\begin{array}{c}\text { AIS 3 } \\
(\mathbf{\%})\end{array}$ & $\begin{array}{c}\text { AIS 4 } \\
(\mathbf{\%})\end{array}$ & $\begin{array}{c}\text { AIS 5 } \\
(\%)\end{array}$ & $\begin{array}{c}\text { AIS 6 } \\
(\%)\end{array}$ \\
\hline \multirow{3}{*}{ Head } & 3 & 243 & 33 & 11 & 4 & 0 & 0 & 0 \\
surrogate & 3.5 & 521 & 82 & 41 & 12 & 4 & 0 & 0 \\
& 3.9 & 842 & 98 & 80 & 38 & 10 & 2 & 0 \\
& 4.4 & 1245 & 100 & 96 & 77 & 33 & 7 & 0 \\
Human & 3 & 446 & 72 & 31 & 10 & 2 & 0 & 0 \\
head & 3.5 & 625 & 90 & 55 & 20 & 5 & 0 & 0 \\
& 3.9 & 978 & 99 & 89 & 52 & 16 & 3 & 0 \\
\hline
\end{tabular}

\section{Discussion}

Relevant observations can be drawn from this study in order to analyze the effectiveness of current standards to prevent head injuries, the anvil influence, and the relationship between impact velocity during the impact process and head injury probability

\subsection{Effectiveness of Current Standards to Prevent Head Injuries}

The analysis in Section 3.1 reveals that, although combat helmets may satisfy ballistic standards (STANAG 2920 [5] or NIJ 0106.01 [6]), the helmet's performance in blunt conditions is different. This study is carried out using the same configuration as the combat helmet analyzed in other studies $[12,30,32,33]$, complying with the requirements imposed by ballistic standards. However, standards with low impact conditions such as the ECE R22/05 standard [19] and the NHTSA [43] have not been sufficiently studied and reveal specific considerations. The results obtained with simulations for the surrogate configuration carried out in this paper show a good correlation with data provided by a helmet manufacturer and the results from [23]. The differences observed on frontal and rear impacts with the experimental test can be due to the different possible adjustments of the pads and the support system or also due to the location of impact, which can vary significantly depending on the exact location when striking against the anvil. However, these values are similar to those obtained in simulations with the ACH helmet in front, rear, and side impact, carried out by Fitek and Meyer [23], as shown in Figure 11.

Therefore, the results show that the current shell configuration has a high probability of causing mild traumatic brain injury to its wearer. We do not suggest changing the material of the helmet, but we do consider that further research should be focused on the internal system of the helmet (foams pads) since, in specially designed helmets for blunt impact, such as in motorbike and bicycle helmets, the internal system is generally made of materials that are different from those used in the ballistics field.

The present results highlight the need to consider the use of human head numerical models in current combat helmet testing methodologies to obtain more information about brain damage, as well as other parameters that have not been included in this work. Understanding the behavior of the different parts of the combat helmet and the interaction with a human head model may improve the knowledge of combat helmets' behavior, leading to more efficient developments.

The ECE R22/05 standard [19] defines a threshold acceleration that helmet manufacturers must achieve, ensuring that helmets have to be at least as safe as the standard deems. Nevertheless, the results obtained suggest that, under standardized impact conditions, there is a high probability of multiple head injury modes occurring, even with the helmet meeting the standard thresholds, particularly, 
in the top helmet location. Thus, it is suggested to assess the safety level on standards based on an AIS curve rather than only measuring the peak linear acceleration.

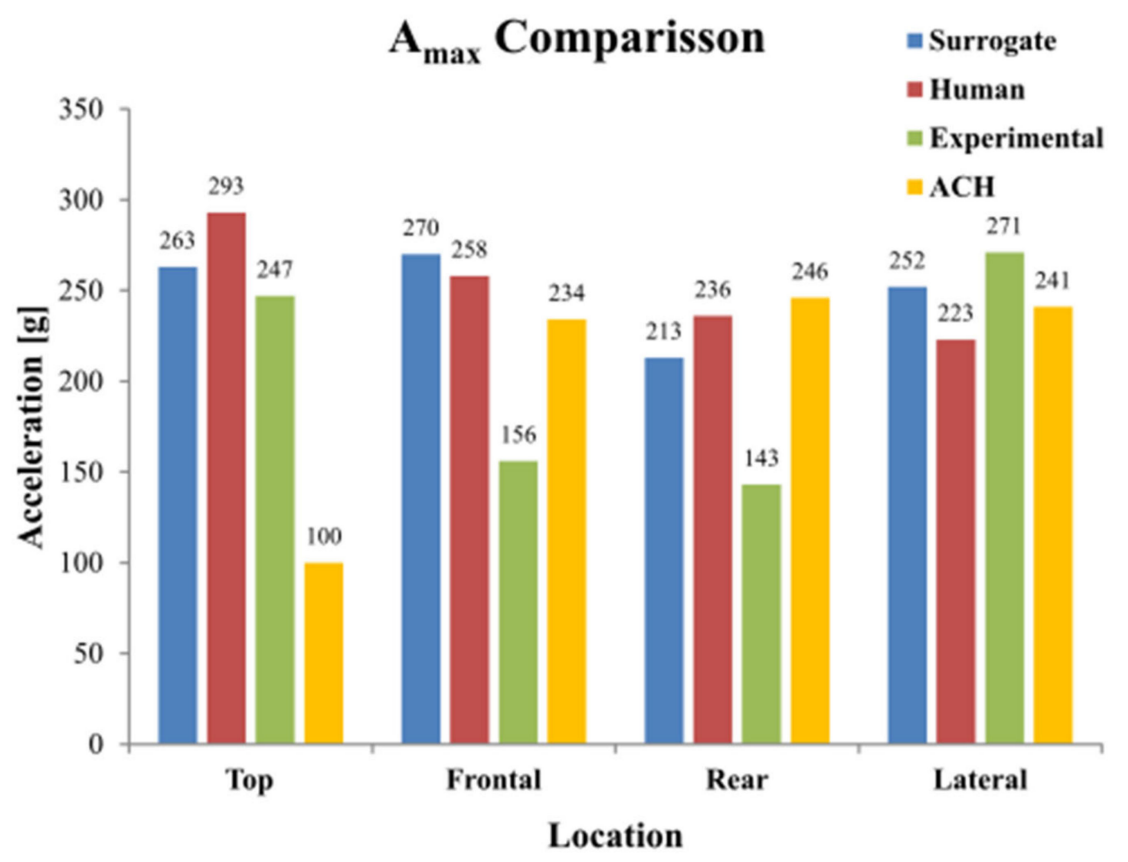

Figure 11. PLA of both head models and experimental data for each impact location using the head surrogate, the human head model, experimental data, and an advanced combat helmet (ACH).

\subsection{The Impact Surface's Influence}

The influence of the anvil's shape on the peak linear accelerations obtained has not been shown to be particularly relevant, as reflected in Figure 12. Thus, the flat surface tests may be sufficient to perform an analysis of the performance of a combat helmet under blunt impacts.

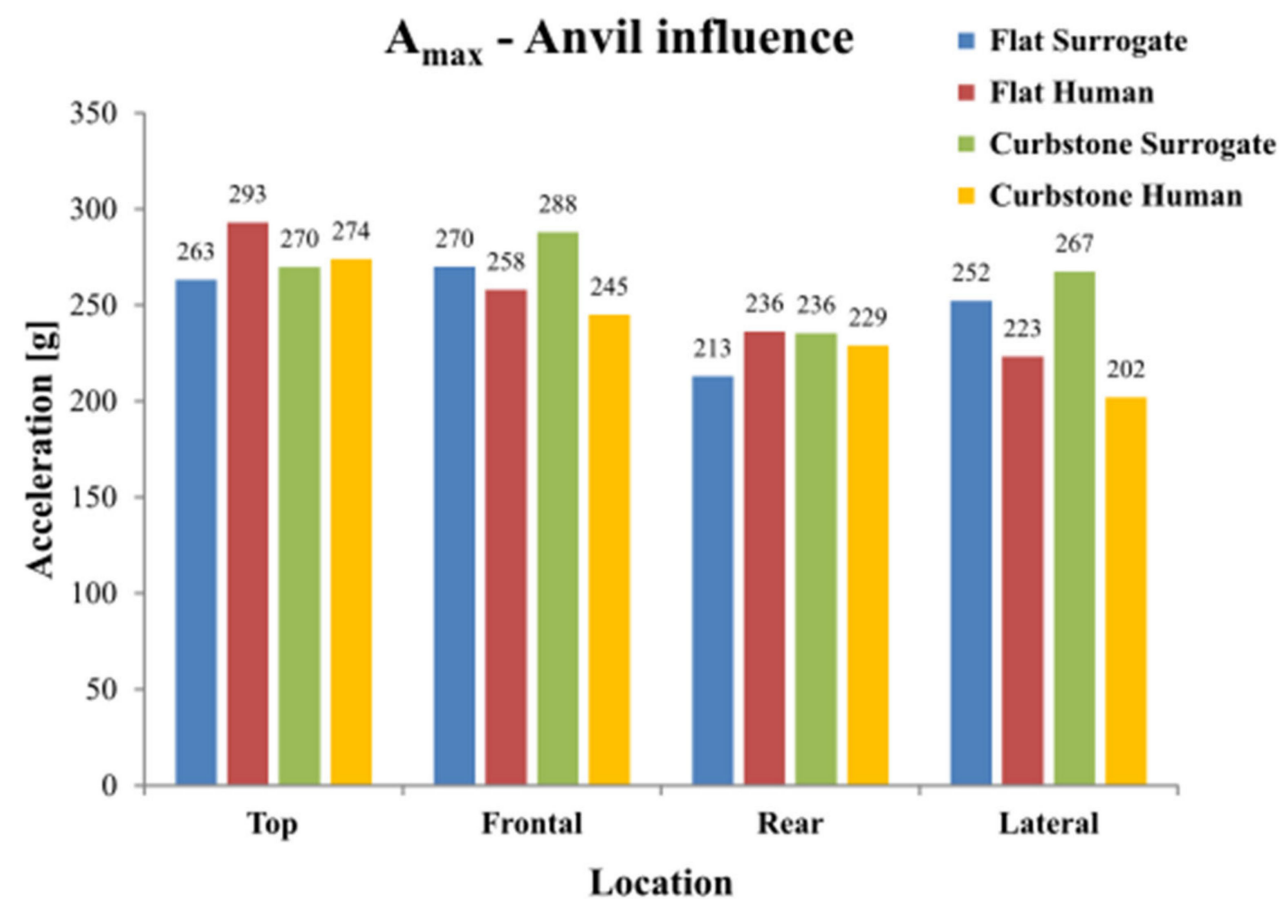

Figure 12. Comparison between two head models used at $4.4 \mathrm{~m} / \mathrm{s}$ for different anvil's geometry. 


\subsection{Relationship between Impact Velocity and Head Injury Probability}

The impact velocity is an important parameter to consider in the design of helmets and may be decisive in the event of a sudden fall. The helmet and its internal system are the components that must absorb impact energy. A linear relationship is found between the PLA on both head models and the impact velocity for the current combat helmet, as shown in Figure 13. Under conditions of impact velocities of $4.4 \mathrm{~m} / \mathrm{s}$ (equivalent to $15.84 \mathrm{~km} / \mathrm{h}$ ), the probabilities of suffering damage are moderate. However, by decreasing the impact velocity to $3.5 \mathrm{~m} / \mathrm{s}$, the current helmet configuration provides high performance.

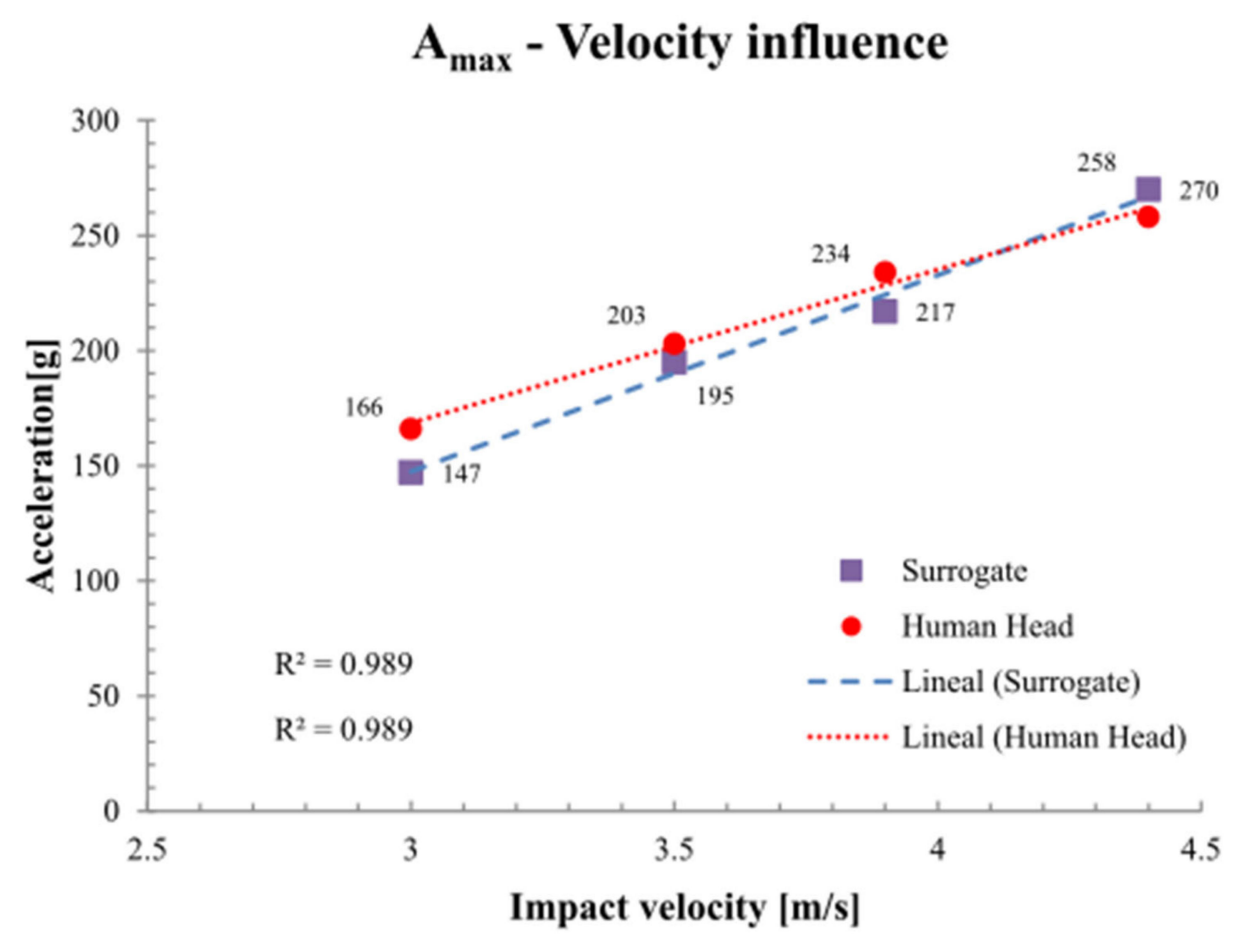

Figure 13. PLA at different frontal impact velocities for the human head.

Therefore, with the current combat helmet configuration, it is not advisable to use it at impact velocities beyond $3.5 \mathrm{~m} / \mathrm{s}$, as a motorbike helmet, for instance, because considerable brain damage may be caused.

\section{Conclusions}

In summary, the current study examined how changes in the head model could lead to differences in traumatic brain injury (TBI) under blunt impact conditions. Two head models were used, i.e., a standardized head surrogate by the ECE R22.05 standard and a realistic human head model. To observe the influence of the impact zone on the degree of injury induced to the wearer, drop impacts were carried out at the following four locations: front, top, rear, and side. Peak linear acceleration, HIC, and AIS scale level were used to analyze the TBI.

The differences in the results between the human head and head surrogate configurations may be due to various reasons, for example, head mass and geometry. In this study, the human head model used was obtained for a real person; however, the head surrogate was imposed by motorcycle helmet standards. For these reasons, the human head results are slightly higher than the experimental and head surrogate results.

Regarding compliance with regulations, complying with the limits established by the ECE R22/05 standard does not exempt the user from suffering injuries from low impact velocity, such as falls or blows, which are not severe but are harmful and cause TBI. 
Followed by analyzing the peak linear acceleration and HIC (this last one according to the ECE R22/05 standard and the NHTSA regulation), the restrictions imposed by the regulations are satisfied in practically all cases for the head surrogate model. However, for the human head model, it complies with the criteria imposed by European Regulations regarding acceleration and HIC $(<2400)$, but not in the case of the NHTSA standard, because it is higher in all impact locations than HIC 1000. With regard to anvil geometry, a change in the morphology of the impact surface does not generate large variations in TBI.

Therefore, the current configuration of a combat helmet does not provide high drop performance. The standards applied are especially designed for motorbike helmets. Consequently, to improve the impact performance of current combat helmets, their configuration should be modified. Foam pads may have an important role to play in future research for reducing brain injury rates.

Author Contributions: Conceptualization, J.A.L., Á.O., and M.R.M.; methodology, C.M.-G., M.R.M., and I.R.; simulations, C.M.-G. and J.A.-M.; experimental data, Á.O; investigation, J.A.-M., C.M.-G., and M.R.M.; writing-review and editing J.A.-M., J.A.L, Á.O., C.M.-G., I.R., and M.R.M.; supervision, J.A.L, M.R.M. and J.A.-M.; funding acquisition, M.R.M. All authors have read and agreed to the published version of the manuscript.

Funding: This work has been carried out within the framework of the research project DPI2017-88166-R of the FEDER program financed by the Ministerio de Economía, Industria y Competitividad and the Spanish Ministry of Education, Culture and Sports for the professor's mobility program José Castillejo's 2018 grant (CAS18/00292).

Acknowledgments: The authors acknowledge the Ministry of Economy and Competitiveness of Spain and the FEDER program under the Project DPI2017-88166-R for their financial support of this work and the Spanish Ministry of Education, Culture, and Sports for the professor's mobility program José Castillejo's 2018 grant (CAS18/00292). The authors also acknowledge the FECSA for the experimental data.

Conflicts of Interest: The authors declare no conflict of interest.

\section{References}

1. Cernak, I.; Noble-Haeusslein, L.J. Traumatic Brain Injury: An Overview of Pathobiology with Emphasis on Military Populations. J. Cereb. Blood Flow Metab. 2010, 30, 255-266. [CrossRef] [PubMed]

2. Elder, G.A.; Cristian, A. Blast-related mild traumatic brain injury: Mechanisms of injury and impact on clinical care. Mt. Sinai J. Med. A J. Transl. Pers. Med. 2009, 76, 111-118. [CrossRef] [PubMed]

3. Hopping, J.; Bass, C.R.D.; Shridharani, J.; Perritt, C.; Haynes, N.; Masters, K. Methodologies for Blunt Trauma Assessment in Military Helmets. In Proceedings of the Personal Armour Systems Symposium, Quebec, Canada, 13-17 September 2010; pp. 1-12.

4. Knapik, J.J.; Steelman, R.; Grier, T.; Graham, B.; Hoedebecke, K.; Rankin, S.; Klug, K.; Proctor, S.; Jones, B.H. Military Parachuting Injuries, Associated Events, and Injury Risk Factors. Aviat. Space Environ. Med. 2011, 82, 797-804. [CrossRef] [PubMed]

5. NATO Standarization Agency. STANAG 2920 PPS (Edition 2)—Ballistic Test Method for Personal Armour Materials and Combat Clothing; NATO Standarization Agency: Brussels, Belgium, 2003.

6. U.S. Department of Justice. National Institute of Justice NIJ Standard-0106.01; Department of Justice: Washington, DC, USA, 1981.

7. Palta, E.; Fang, H.; Weggel, D.C. Finite element analysis of the Advanced Combat Helmet under various ballistic impacts. Int. J. Impact Eng. 2018, 112, 125-143. [CrossRef]

8. Miranda-Vicario, A.; Bravo, P.M.; Coghe, F. Experimental study of the deformation of a ballistic helmet impacted with pistol ammunition. Compos. Struct. 2018, 203, 233-241. [CrossRef]

9. Cai, Z.; Huang, X.; Xia, Y.; Li, G.; Fan, Z. Study on behind Helmet Blunt Trauma Caused by High-Speed Bullet. Appl. Bionics Biomech. 2020, 2020. [CrossRef] [PubMed]

10. Tan, L.B.; Tse, K.M.; Lee, H.P.; Tan, V.B.C.; Lim, S.P. Performance of an advanced combat helmet with different interior cushioning systems in ballistic impact: Experiments and finite element simulations. Int. J. Impact Eng. 2012, 50, 99-112. [CrossRef]

11. Rubio, I.; Rodríguez-Millán, M.; Marco, M.; Olmedo, A.; Loya, J.A. Ballistic performance of aramid composite combat helmet for protection against small projectiles. Compos. Struct. 2019, 226. [CrossRef] 
12. Rodriguez-Millan, M.; Ito, T.; Loya, J.A.; Olmedo, A.; Miguelez, M.H. Development of numerical model for ballistic resistance evaluation of combat helmet and experimental validation. Mater. Des. 2016, 110, $391-403$. [CrossRef]

13. Bass, C.D.; Davis, M.; Rafaels, K.; Rountree, M.S.; Harris, R.M.; Sanderson, E.; Andrefsky, W.; Dimarco, G.; Zielinski, M. A Methodology for Assessing Blast Protection in Explosive Ordnance Disposal Bomb Suits. Int. J. Occup. Saf. Ergon. 2005, 11, 347-361. [CrossRef]

14. Zhang, L.; Makwana, R.; Sharma, S. Brain response to primary blast wave using validated finite element models of human head and advanced combat helmet. Front. Neurol. 2013, 4, 88. [CrossRef] [PubMed]

15. Rodríguez-Millán, M.; Tan, L.B.; Tse, K.M.; Lee, H.P.; Miguélez, M.H. Effect of full helmet systems on human head responses under blast loading. Mater. Des. 2017. [CrossRef]

16. Tse, K.M.; Tan, L.B.; Lee, S.J.; Lim, S.P.; Lee, H.P. Investigation of the relationship between facial injuries and traumatic brain injuries using a realistic subject-specific finite element head model. Accid. Anal. Prev. 2015, 79, 13-32. [CrossRef] [PubMed]

17. Dionne, J.P.; Levine, J.; Makris, A. Acceleration-based methodology to assess the blast mitigation performance of explosive ordnance disposal helmets. Shock Waves 2018, 28, 5-18. [CrossRef]

18. Maach, S.; Von Rosen, B.; Mccauley, L.; Levine, J.; Dionne, J.-P. Comparison of Hybrid III Head Response to Shock Tube and Explosive Blast Loading. In Proceedings of the IRCOBI Conference Proceedings, Antwerp, Belgium, 13-15 September 2017.

19. (UNECE), U.N.E.C. for E. ECE 22 05, Uniform Provision Concerning the Approval of Protective Helmets and Their Visors for Driver and Passengers of Motor Cycles and Mopeds; (UNECE), U.N.E.C. for E: Geneva, Switzerland, 2002; pp. 1-11.

20. BSI Standards Publication. Helmets for Pedal Cyclists and for Users of Skateboards and Roller Skates; BSI Standards Publication: London, UK, 1997.

21. Begonia, M.; Rooks, T.; Pintar, F.A.; Yoganandan, N. Development of a Methodology for Simulating Complex Head Impacts with the Advanced Combat Helmet. In Proceedings of the Military Medicine; Oxford University Press: Oxford, UK, 2019; Volume 184, pp. 237-244.

22. Barlow, G.J.; Page, C.; Drane, P.; Stapleton, S.E.; Fasel, B.; Inalpolat, M. Combat helmet liner design for blunt impact absorption using multi-output Gaussian process surrogates. Proc. Inst. Mech. Eng. Part C J. Mech. Eng. Sci. 2020. [CrossRef]

23. Fitek, J.; Meyer, E. Design of a Helmet Liner for Improved Low Velocity Impact Protection. Semant. Sch. 2013. [CrossRef]

24. McEntire, B.J.; Whitley, P. Blunt Impact Performance Characteristics of the Advanced Combat Helmet and the Paratrooper and Infantry Personnel Armor System for Ground Troops Helmet. Semant. Sch. 2005. [CrossRef]

25. Staniszewski, J.; Walter, M.; Plaisted, T. Improved Low-Velocity Impact Performance of the Advanced Combat Helmet (ACH) at $17 \mathrm{ft} / \mathrm{s}$ through Optimization of Pad Material Response; Technical Report 2019; CCDC Army Research Laboratory Aberdeen Proving Ground United States: Aberdeen Proving Ground, MD, USA, 2019.

26. Sepulveda-Lopez, D.; Antona-Makoshi, J.; Rubio, I.; Rodríguez-Millán, M. Numerical Analysis of Bicycle Helmet under Blunt Behavior. Appl. Sci. 2020, 10, 3692. [CrossRef]

27. Antona-Makoshi, J. Traumatic Brain Injuries: Animal Experiments and Numerical Simulations to Support the Development of a Brain Injury Criterion; Division of Vehicle Safety, Chalmers tekniska högskola: Göteborg, Sweden, 2016; ISBN 9789162898489.

28. Van Hoof, J.; Cronin, D.S.; Worswick, M.J.; Williams, K.V.; Nandlall, D. Numerical head and composite helmet models to predict blunt trauma. In Proceedings of the 19th International Symposium on Ballistics, Interlaken, Switzerland, 7-11 May 2001; pp. 7-11.

29. Rubio, I.; Díaz-álvarez, A.; Bernier, R.; Rusinek, A.; Loya, J.A.; Miguelez, M.H.; Rodríguez-Millán, M. Postmortem analysis using different sensors and technologies on aramid composites samples after ballistic impact. Sensors 2020, 20, 2853. [CrossRef]

30. Tham, C.Y.; Tan, V.B.C.; Lee, H.P. Ballistic impact of a KEVLAR ${ }^{\circledR}$ helmet: Experiment and simulations. Int. J. Impact Eng. 2008, 35, 304-318. [CrossRef]

31. Palomar, M.; Lozano-Mínguez, E.; Rodríguez-Millán, M.; Miguélez, M.H.; Giner, E. Relevant factors in the design of composite ballistic helmets. Compos. Struct. 2018, 201, 49-61. [CrossRef]

32. Chang, F.-K.; Chang, K.-Y. A Progressive Damage Model for Laminated Composites Containing Stress Concentrations. J. Compos. Mater. 1987, 21, 834-855. [CrossRef] 
33. Chang, F.-K.; Chang, K.-Y. Post-Failure Analysis of Bolted Composite Joints in Tension or Shear-Out Mode Failure. J. Compos. Mater. 1987, 21, 809-833. [CrossRef]

34. Li, Y.Q.; Li, X.G.; Gao, X.L. Modeling of advanced combat helmet under ballistic impact. J. Appl. Mech. Trans. ASME 2015, 82. [CrossRef]

35. Li, X.G.; Gao, X.L.; Kleiven, S. Behind helmet blunt trauma induced by ballistic impact: A computational model. Int. J. Impact Eng. 2016, 91, 56-67. [CrossRef]

36. McElhaney, J.H.; Roberts, V.L.; Hilyard, J.F. Handbook of Human Tolerance (1976 edition); Japan Automobile Research Institute: Tsukuba, Japan, 1976.

37. Melvin, J.W.; Yoganandan, N. Biomechanics of Brain Injury: A Historical Perspective; Springer: New York, NY, USA, 2015; ISBN 9781493917327.

38. Jin, X.; Yang, K.H.; King, A.I. Mechanical properties of bovine pia-arachnoid complex in shear. J. Biomech. 2011, 44, 467-474. [CrossRef]

39. Arbogast, K.B.; Margulies, S.S. Material characterization of the brainstem from oscillatory shear tests. J. Biomech. 1998, 31, 801-807. [CrossRef]

40. Brolin, K.; Halldin, P. Development of a Finite Element Model of the Upper Cervical Spine and a Parameter Study of Ligament Characteristics. Spine 2004, 29, 376-385. [CrossRef]

41. Yoganandan, N.; Kumaresan, S.; Pintar, F.A. Geometric and Mechanical Properties of Human Cervical Spine Ligaments. J. Biomech. Eng. 2000, 122, 623-629. [CrossRef]

42. Chinn, B.; Canaple, B.; Derler, S.; Doyle, D.; Shuller, E.; Willinger, R. COST 327 Motorcycle Safety Helmets; European co-operation in the Field of Scientific and Technical Research; Office for Official Publications of the European Communities: Brussels, Belgium, 2001.

43. Eppinger, R.; Sun, E.; Bandak, F.; Haffner, M.; Khaewpong, N.; Maltese, M.; Kuppa, S.; Nguyen, T.; Takhounts, E.; Tannous, R.; et al. Development of Improved Injury Criteria for the Assessment of Advanced Automotive Restraint Systems - II; National Highway Traffic Safety Administration: Washington, DC, USA, 1999.

44. Hayes, W.C.; Erickson, M.S.; Power, E.D. Forensic Injury Biomechanics. Annu. Rev. Biomed. Eng. 2007, 9, 55-86. [CrossRef]

Publisher's Note: MDPI stays neutral with regard to jurisdictional claims in published maps and institutional affiliations.

(C) 2020 by the authors. Licensee MDPI, Basel, Switzerland. This article is an open access article distributed under the terms and conditions of the Creative Commons Attribution (CC BY) license (http://creativecommons.org/licenses/by/4.0/). 